\section{YOUR JOURNEY STARTS HERE}

British Academy of Cosmetic Dentistry (BACD)

Membership Director David Watson says the BACD's ethos is 'to never lose the enthusiasm to want to better yourself. Love what you do and take pride in your work.' Join the BACD and get connected to a world of opportunity and inspiration.

No matter what stage of your career you are at, membership offers a plethora of benefits. For the more experienced dentist, the BACD will help you further develop your passion. For example, new for 2015 are masterclass courses with globally renowned speakers aimed at 'top end' practitioners who never want to stop refining their practice.

If you are a young dentist or student, networking with BACD dentists allows you to tap into the knowledge of some of the most respected practitioners in the industry. With the Academy's support, find your focus and hit the ground running.

Become a part of the BACD and begin an exciting journey towards professional and personal fulfilment. For further information, call 0207612 4166, fax 0207 182 7123, email Suzy Rowlands at suzy@bacd.com or visit www.bacd.com.

\section{BE HPV AWARE}

The number of reported cases of human papillomavirus (HPV) is rapidly increasing, and its links to oral cancer provide great cause for concern amongst the dental profession. Up to eight out of ten people will be infected by HPV during their lives, but many strains of the virus are not dangerous and will often go undetected. It is those associated with cancer that are most worrying, with some strains found in more than 30\% of patients with oropharyngeal cancer.

Vigilance and careful attention to detail are imperative during opportunistic screening for oral cancer, and it is important to refresh and update your knowledge and skills regularly. The interactive oral cancer module designed by IDH and the Association of Dental Groups (ADG) is the ideal tool for this, helping to raise awareness and understanding of oral cancer. It is completely free to all healthcare professionals in the UK, and those who seek a CPD certificate need only pay $£ 25$ excluding VAT, $£ 5$ of which will be sent directly to the British Dental Health Foundation.

Make sure you are prepared for the fight against oral cancer: to find out more about the free oral cancer training available visit http://www.dentalgroups.co.uk/mouth_cancer.php.

For more information about the ADG visit www. dentalgroups.co.uk.

1. Kreimer A R, Johansson M, Waterboer T et al. Evaluation of human papillomavirus antibodies and risk of subsequent head and neck cancer. J Clin Oncol 2013; 31: 2708-2715.

\section{WE CARE ABOUT YOU}

As a dental professional you will know how important it is not just to provide exceptional dentistry, but to build a good relationship with your patients too. At Goodman Grant Lawyers for Dentists we realise it is vital to resolve legal matters with a technically excellent job but we also care about you and your practice.

Goodman Grant aims to build a close connection with you, take away the strain of legal proceedings, put you at ease and keep you informed, every step of the way. We understand that your priority is your clinical business, so we provide a team of specialist dental lawyers that are available from early morning to late evening to speak to you at a time that is convenient to you.

Goodman Grant has over 75 years combined experience of dental-sector-specific expertise to ensure that you receive outstanding advice with any legal matter. Contact us today and let us take away your worries.

For more information call Ray Goodman on 0151707 0090, email rng@goodmangrant.co.uk, or John Grant on 01138343705 , emailjmg@goodmangrant.co.uk. Alternatively, visit www.goodmangrant.co.uk.

\title{
STRUCTURED ORTHODONTIC TRAINING FOR DENTISTS
}

The IAS Academy provides a unique guided pathway of lifetime learning for general dental practitioners, with a point of entry for every level of orthodontic experience.

Professor Ross Hobson, who will teach the advanced level, said: 'This is not a "We will fix your teeth in weeks" approach; our aim is proper assessment, diagnosis, treatment planning and appropriate treatment.'

Leading the way in anterior alignment orthodontics (AA0), Dr Tif Qureshi said: 'We have created a pathway of learning using the same protocols of arch evaluation that we teach with Inman Aligner - digital planning, printing and evaluation.

'All the trainers are able to access every case from a digital vault - assessment will be mandatory at every level. Being quali- fied to provide the appliance will require a combination of education, support and clinical experience.'

The IAS Academy offers an outstanding level of teaching, enabling you to give your patients choice and stable results. For more information, visit www.iasortho. com, emailinfo@iasortho.com or telephone 08453665477.

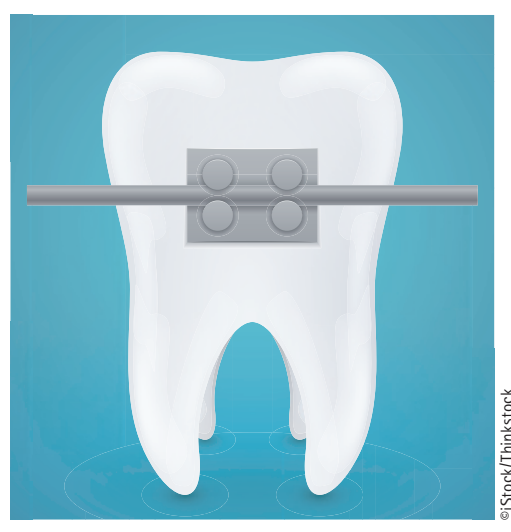

\section{IMPROVING THE VALUE OF YOUR PRACTICE}

If you are struggling to meet NHS UDA performance figures or you are practising in an over commissioned area, it could have a fundamental impact on the underlying profitability, goodwill and value of your practice.

However, Dental Elite can help with advice from an experienced team of expertly trained practice consultants. Dental Elite is one of the largest specialist dental practice sales agencies in the UK.

Call now to arrange a free of charge valuation. To find out more visit www.dentalelite.co.uk, email info@dentalelite.co.uk or call 01788545900. 